rev.relac.int.estrateg.segur.8(1):327-347,2013

\title{
DE ZETAS A MARAS. CONCEPCIONES DE MAFIA Y CRIMEN ORGANIZADO EN AMÉRICA LATINA*
}

\author{
Luis Alexander Montero Moncada* \\ Liana Abril Pérez ${ }^{* * *}$ \\ Ángela Herrera ${ }^{* * *}$
}

\section{RESUMEN}

Este artículo pretende realizar una definición teórica de los grupos Zetas y Maras para enmarcarlos como mafias o grupos de crimen organizado, susceptibles de una caracterización de nueva insurgencia. Para esto, se recurre a elementos teóricos planteados para caracterizar diferentes mafias en el sistema internacional, fundamentalmente la mafia siciliana. Posteriormente se analiza, de una manera comparada,

* Articulo resultado de investigación asociado al proyecto titulado "Evolución de la doctrina de contrainsurgencia de 1947 a 2011". Escuela Militar de Cadetes. Dirección de Investigaciones, 2012.

** Politólogo con énfasis en Relaciones Internacionales. Magister en Análisis de Problemas Políticos, Económicos e Internacionales Contemporáneos. PhD. en Estudios Políticos y Relaciones Internacionales. Director de Investigaciones de la Escuela Militar de Cadetes. Profesor e Investigador experto en Seguridad, Defensa y Operaciones Especiales. Alexander.montero@gmail.com

*** Profesional en Relaciones Internacionales y Estudios Políticos. Especialista en Administración Financiera. Actualmente se desempeña como investigadora de la Dirección de Investigaciones de la Escuela Militar de Cadetes General José María Córdova. investigacionasesor4@esmic.edu.co

**** Profesional en Relaciones Internacionales y Estudios Políticos. Especialista en Ambiente y Desarrollo local. Actualmente se desempeña como investigadora de la Dirección de Investigaciones de la Escuela Militar de Cadetes General José María Córdova. anmaheca@gmail.com 
los riesgos y amenazas que estas dos agrupaciones plantean desde un punto de vista asimétrico. La conclusión a la cual se llega, es que los Zetas mexicanos tienen más elementos teóricos para ser definidos como una mafia, propiamente dicha, mientras que los Maras son más puramente organizaciones de crimen organizado. No obstante, tanto los Zetas, por su carácter de fuerza especial al servicio del crimen, como los Maras, por su des-territorialidad y características sociales, deben ser tenidos en cuenta como amenazas asimétricas a nivel regional.

Palabras clave: Mafia, Crimen Organizado, violencia privada, narcotráfico, amenaza asimétrica.

\title{
FROM ZETAS TO MARAS. THOUGHTS OF MAFIA AND ORGANIZED CRIME IN LATIN AMERICA
}

\begin{abstract}
This paper aims to propose a theoretical definition of the so-called groups Zetas and Maras, as gangs or organized crime groups, susceptible to be featured as new insurgencies. For that purpose, it is resorted to theoretical elements that have been used to portray different mafias, i.e. the Sicilian Mafia, and then a comparative analysis is made of risks and threats posed by these two groups from an asymmetric perspective. All in all, a conclusion is reached that Mexican Zetas have more theoretical elements to be defined as a Mafia, unlike Maras, which must be called a crime organization. Anyway, both Zetas, because of their special power to commit crimes, and Maras, by being non-territorial and by their social characteristics, should be taken into account as regional asymmetric threats.
\end{abstract}

Keywords: Mafia, Organized Crime, private violence, drug trafficking, asymmetric threat.

\section{DE ZETAS A MARAS. CONCEPÇÕES DE MAFIA E CRIME ORGANIZADO NA AMÉRICA LATINA}

\section{RESUMO}

Este ensaio pretende fazer uma definição teórica dos grupos Zetas e Maras para enquadrá-los como máfias ou grupos de crime organizado, passíveis de caracterização como uma nova insurgência. Para isso, usamos elementos teóricos para caracterizar diferentes máfias no sistema internacional, fundamentalmente, a máfia siciliana. Posteriormente, analisam-se, de uma maneira comparada, os riscos e ameaças que estes dois grupos representam desde um ponto de vista assimétrico. A conclusão estabelecida é que os Zetas mexicanos têm mais elementos teóricos 
para ser definidos como uma máfia, propriamente dita, enquanto que os Maras estão mais próximos ao crime organizado. No entanto, tanto os Zetas, devido ao seu caráter de força especial ao serviço do crime, como os Maras, por sua não territorialidade e características sociais, devem ser levados em consideração como ameaças assimétricas regionais.

Palavras-chave: máfia, crime organizado, violência privada, tráfico de drogas, ameaça assimétrica.

\section{INTRODUCCIÓN}

El crimen organizado en América Latina ha acompañado la historia regional casi desde los inicios mismos de la vida republicana de los países latinoamericanos e incluso en América del Norte. De hecho, es posible afirmar que las estructuras de crimen organizado en los países latinoamericanos tienen una estrecha relación bien sea en sus orígenes o ya sea en su sostenimiento con estructuras de crimen organizado en Estados Unidos, evidenciando así una relación indisoluble.

En los inicios del siglo XXI, se revalida esta relación en el marco de problemas transnacionales como el narcotráfico y problemas de seguridad urbana que si bien tienen su esfera de acción inmediata dentro del espectro subregional, algunos de ellos tuvieron origen común en Estados Unidos. De esta manera, agrupaciones criminales como los Zetas, en México, o los Maras (MS o 18) en Honduras y El Salvador, nacidas dentro de Estados Unidos o bajo influencia directa de este, han sido especialmente conocidas debido a la crudeza de sus acciones y a los retos que plantean en materia de seguridad no solo a los gobiernos que directamente les compete su combate, sino a toda la subregión, debido a los enlaces que han realizado estos grupos con otras agrupaciones criminales.

Por tal motivo, el propósito del presente ensayo es realizar un análisis comparado entre estas dos estructuras criminales, Zetas y Maras (MS y 18), determinando, a través del estudio de sus estructuras y acciones, su acertada o errónea clasificación como mafias propiamente dichas.

Para este fin, el periodo de estudio a trabajar abarca el periodo 1998-99 hasta septiembre de 2010, momentos en los cuales resulta metodológicamente fácil superponer las historias de estas dos agrupaciones criminales. En un primer momento se realizará una caracterización analítica de los Zetas, enmarcándolos dentro de algunos conceptos propios del crimen organizado, para luego realizar esta misma acción con las Maras. Posteriormente, se confluirá sobre la discusión de su validez o no como grupos mafiosos propiamente dichos, para finalizar con un análisis de la amenaza que estos grupos representan dentro del marco de la guerra asimétrica. 


\section{LOS ZETAS, LA PRIVATIZACIÓN DEL EJERCICIO DE LA PROTECCIÓN POR MEDIO DE LA VIOLENCIA Y LA INTIMIDACIÓN}

En el lenguaje simple, narcotraficante se asocia con mafioso, e incluso llega a igualarse. Dicha denominación caracterizó los procesos narcotraficantes en la región andina, especialmente en Colombia bajo la influencia de los carteles y de Pablo Escobar. De la misma manera en México, los conceptos se traslapan para hacer referencia a los diferentes carteles involucrados en el negocio de las drogas y a grupos armados al servicio del narcotráfico como Los Zetas. Sin embargo, dicha intersección de términos, que no es la más acertada desde el punto de vista teórico, llega a producir distorsiones conceptuales que dificultan la adecuada comprensión de los diferentes fenómenos de la violencia en México.

En ese sentido, el mafioso debe caracterizarse como aquel que se dedica a la actividad de la protección privada, o, en otras palabras, quien ofrece el recurso de la violencia y la protección en una forma simbiótica. Gambetaes un poco más ambicioso sobre este concepto y en su definición plantea que "el mafioso es un empresario especial que protege la limpieza de las transacciones a cambio de una recompensa que puede obtener de ambas partes"(2010: 51). Esta mención implica el hecho en sí mismo de una protección especial a quien se encarga de transferir un bien o un servicio, generalmente en el marco de la ilegalidad o en una zona gris muy difusa, y también a quien lo recibe, otorgándole una credibilidad a la transacción.

De igual manera, la protección ofrecida por el mafioso implica protección frente a posibles competidores. Al respecto, Los Zetas fueron una eficiente herramienta de disuasión para ahuyentar amenazas serias tanto para Cárdenas Guillén como para la estructura central de la organización, hasta la muerte de Z1 Arturo Guzmán Decena, máximo líder militar. El hecho de la protección cerrada, lo analiza Gambeta (2010: 56) de manera que rara vez un mafioso limita su espectro de protección a un solo cliente o demandante de seguridad (aunque esto pareciera ser característica de los Zetas); la protección sin embargo es limitada.

Adicionalmente, la venta de protección como venta de un servicio implica cierta incertidumbre en cuanto al uso real de dicho servicio. En otras palabras, tanto el mafioso como el Estado ofrecen protección en función de ser un derecho que queremos usar cuando sea necesario, y, en consecuencia, se puede pagar solo por gozar de una idea de protección pero no por una protección real (Gambeta, 2010: 63).

Este punto es significativamente importante en el estudio de agrupaciones como Los Zetas. Su origen estatal, motivado dentro de los parámetros de venta de seguridad por parte del Estado mexicano, hicieron que el tránsito hacia la ilegalidad fuera mucho más sencillo y solo fuera pasar de la esfera pública a la privada en muchos casos. 
Al respecto, Carlos Resa Nastares afirma que:

Lo característico de la industria de la protección en el México pos-revolucionario ha sido que su funcionamiento ha estado acotado a los funcionarios públicos o a quienes éstos otorgaban una licencia de protección. Los agentes privados, incluidos los narcos, no han sido capaces de asentarse en los mercados de la protección sin la cobertura estatal. En sentido contrario, algunos actores públicos en México han ejercido a un tiempo la protección a narcos y han sido narcos ellos mismos. Otros fueron protectores primero y narcos después. La nómina de la Dirección Federal de Seguridad es prolija en ejemplos, comenzando por los dos que más alto llegaron en el mundo de la compra-venta de drogas, Rafael Chao López y Rafael Aguilar Guajardo. (Nastares, s.f.).

En su recorrido como grupo militar inicialmente hasta un grupo altamente especializado en la industria de la protección privada al servicio del narcotráfico mexicano, Los Zetas no han seguido, sin embargo, el modelo generalizado de hacer el salto desde instancias públicas dedicadas a vender protección hasta las instancias privadas. En primer lugar, el origen de los Zetas instituyó un monopolio de la demanda, concentrada en la protección de Osiel Cárdenas Guillén (Nastares, s.f.: 3), uno de los principales narcotraficantes mexicanos de fines de los 90 e inicios del siglo XXI, quien seleccionó dentro de las estructuras militares especializadas (recién incorporadas a las políticas antidrogas mexicanas y en consecuencia fácilmente corruptibles) personal adecuado, con preparación militar, conocimiento de armamento y sus proveedores dentro de Estados Unidos, y sobre todo, acostumbrados al recurso de la extorsión como práctica para conseguir objetivos, de forma tal que así nació este grupo armado. Este monopolio de la demanda, o este monopsonio, llevó sin embargo a varios problemas. El primero, a una dependencia en las ganancias de la actividad mafiosa de protección, al capricho del protegido, y el segundo, a una especialización de la oferta de protección, de manera que los mismos Zetas desconocían detalles de actividades de exportación de narcóticos, de manera que su giro hacia el narcotráfico puro ha sido muy difícil.

En segundo lugar, este monopsonio implicó precisamente que en 2003, luego de la captura de Cárdenas Guillén, los Zetas buscaran una alternativa que reemplazara su única fuente de ingresos. Inicialmente incursionaron en el narcotráfico en pequeña escala, con un alcance exclusivamente barrial, pues desconocían los detalles de rutas, contactos de provisión y distribución, que hábilmente Cárdenas Guillén nunca compartió con ellos. La respuesta fue profundizar el ejercicio de la violencia y la intimidación, que desemboca obligatoriamente en la extorsión. No obstante, su fama como hábiles proveedores de protección los afianzó luego de la captura de Cárdenas. De hecho, el asesinato de siete de los más importantes miembros de Los Texas, una banda rival, con un uso simbólicamente exagerado de la violencia, catapultó nuevamente a los Zetas como oferentes privados de seguridad para las actividades tanto ilegales (no solo narcotráfico sino también migraciones ilegales), como 
legales (venta de vehículos o bienes raíces) o aquellas que quedan en la mitad como la prostitución y el juego.

Sobre el punto del monopsonio, Gambeta afirma que el mafioso no puede optar por ampliar demasiado el abanico de los protegidos pues de ese modo no podría controlar todas las variables y la información en juego correspondiente a cada uno de los actores. Pero tampoco puede limitar al máximo la protección y eliminar toda competencia (o en este caso excluir la competencia de sus favores de protección) para quien compra seguridad y protección, pues se estaría atentando contra el negocio en sí mismo (2010: 54,55). No obstante, este autor también afirma que "la protección privada no se suministra estrictamente con base en la oportunidad, y las oportunidades no siempre llevan a proteger a todas las partes de una transacción" (2010: 57). Al parecer, el camino más sensato es tener un abanico limitado de opciones para ofrecer servicios de mafia.

La consolidación teórica de Los Zetas como mafia, según la interpretación de Carlos Resa (s.f.: 5), dada justo luego de la captura de Osiel Cárdenas, se dio por

Un salto cualitativo el cual está unido a una circunstancia bipolar: por una parte, la conjunción de una demanda y una oferta muy específicas y, por otra, una estrategia empresarial así concebida. En cuanto a este último aspecto, las circunstancias que llevaron a Los Zetas a realizar esta integración vertical del negocio permanecen oscuras. Pero en la conjunción de una oferta y demanda concretas de protección, la situación se asemeja a la que dio origen a la Mafia en Sicilia en el siglo XIX. Del lado de la oferta se encuentran Los Zetas, que son capaces de garantizarla protección a través de una bien demostrada y engrasada habilidad para producir violencia e información. [...] Del otro lado, de la transacción financiera que implica la protección, se sitúa un tejido empresarialsometido a grandes niveles de expropiación de parte de pequeñas y medianas pandillas. En este contexto, [la protección privada y el uso de la violencia de...] Los Zetas puede asimilarse a primera vista a la extorsión, pero va más allá yrepresenta un servicio en toda regla para sus clientes. Los libera del acoso de los pequeños delincuentes,y también de los policías, en un mundo en el que los derechos de propiedad están muydébilmente protegidos por las autoridades públicas.

Adicionalmente, luego de la transición obligada por la muerte de Arturo Guzmán Decena y la captura de Cárdenas Guillén, se puede afirmar que las capacidades de penetración en redes políticas legales de los Zetas, fueron un factor decisivo en su mantenimiento como organización violenta. De hecho, su origen militar ha favorecido la comunicación y los favores entre la organización y sus perseguidores estatales, e incluso ha favorecido también la incorporación constante de militares retirados a las filas criminales. En la política mexicana, los Zetas buscaron y obtuvieron el control de Nuevo Laredo, espacio de operación desde los tiempos de protección 
a Cárdenas Guillen, de manera que las estructuras políticas resultaran favorables. La corrupción, en ese sentido, se convierte en una herramienta fundamental de organizaciones mafiosas, que, como las italianas, permearon grandes sectores políticos italianos, ayudando en parte a su durabilidad en el tiempo (según plantea Dickie, 2007: 97, 109).

Finalmente, el ejercicio mafioso de Los Zetas no se limita exclusivamente al uso de la violencia y la intimidación, sino a la recolección y administración de información a través de complejos procedimientos de inteligencia aprendidos en su pasado militar. Es posible afirmar que los Zetas también venden información de inteligencia a sus protegidos, siendo esta oportuna y contundente, de manera que su prestigio se incrementa con la credibilidad de su información. Precisamente, para Gambeta, la información de inteligencia y de espionaje se convierte en un elemento fundamental del poder y oferta del mafioso que debe demostrar que sabe más que la competencia y puede tenerla a raya (2010: 74,80).

\section{"POR MI MADRE VIVO, POR MI MARA MUERO". LAS MARAS DENTRO DEL CRIMEN ORGANIZADO}

Las Maras, a diferencia de los Zetas, no pueden clasificarse como mafia, puesto que su principal actividad o característica no es el ejercicio de la protección privada, extorsión o tráfico de información. Los Maras se enmarcan más concretamente en una estructura de crimen organizado, con manifestaciones violentas pero sin ser una mafia en términos de Gambeta.

A este respecto, Albanese plantea que "el crimen organizado no existe como tipo ideal, sino como un 'grado' de actividad criminal o como un punto del 'espectro de legitimidad'" (Resa, s.f.). Este planteamiento refiere una gran dificultad para establecer la frontera entre delincuencia común y crimen organizado como tal, puesto que como lo indica Resa Nastares, casi toda actividad delictiva implica algún grado de organización. Tal parece que la frontera la ha establecido el impacto de la actividad criminal y el tamaño y complejidad de la organización.

En la práctica, los códigos penales caracterizan el crimen organizado en función de dos vías. En primer lugar, en función de la comisión del delito, pero, por otro lado, por la pertenencia a la organización criminal per se, independientemente del delito, el cual es juzgado por aparte. Precisamente esta segunda opción ha permitido una gran discusión sobre el carácter de las Maras como organización criminal o simplemente como pandilla o banda criminal. Como se verá más adelante, existen argumentos para plantear que las Maras no inciden significativamente en actividades como el narcotráfico o el tráfico de armas y por lo tanto no pueden ser consideradas como organizaciones criminales. Existen, sin embargo, otros fuertes planteamientos que indican que el hecho que se hayan establecido leyes antimaras en Honduras, El Salvador y Guatemala, que tipifican como delito la simple pertenencia a estos grupos, permiten 
entenderlas como organizaciones criminales a la luz de la segunda vía mencionada. Este mismo camino lo toma el Código Penal Alemán para definir crimen organizado:

Crimen organizado es la violación planificada de la ley al objeto de adquirir beneficios económicos o poder, cuyos delitos son independientemente o en su conjunto de especial gravedad y se llevan a cabo por más de dos participantes que cooperan en el marco de una división laboral por un periodo de tipo prolongado o indeterminado utilizando (a) estructuras comerciales o paracomerciales, o (b) violencia o otros medios de intimidación, o (c) influencia en la política, en los medios de comunicación, en la administración pública, en el sistema de justicia y en la economía legítima (Resa, s.f.).

Las Naciones Unidas ofrecen una matriz de definición sobre el Crimen Organizado bien compleja e interrelacionada. En ese sentido, se define como:

Las actividades colectivas de tres o más personas, unidas por vínculos jerárquicos o de relación personal, que permitan a sus dirigentes obtener beneficios o controlar territorios o mercados, nacionales o extranjeros, mediante la violencia, la intimidación o la corrupción, tanto al servicio de la actividad delictiva como con fines de infiltrarse en la economía legítima, en particular por medio de: (a) el tráfico ilícito de estupefacientes o sustancias sicotrópicas y el blanqueo de dinero, tal como se definen en la Convención de las Naciones Unidas contra el Tráfico Ilícito de Estupefacientes y Sustancias Sicotrópicas de 1998; (b) la trata de personas, tal como se define en el Convenio para la represión de la trata de personas y de la explotación de la prostitución ajena de 1949; (c) la falsificación de dinero, tal como se define en el Convenio internacional para la represión de la falsificación de moneda de 1929; (d) El tráfico ilícito o el robo de objetos culturales, tal como se definen en la Convención sobre medidas que deben adoptarse para prohibir e impedir la importación, la exportación y la transferencia e [sic] propiedad ilícita de bienes culturales de 1970 y la Convención sobre bienes culturales robados o ilegalmente exportados de 1995 del Instituto Internacional para la Unificación del Derecho Privado de las Naciones Unidas para la Educación, la Ciencia y la Cultura; (e) el robo de material nuclear, su uso indebido o la amenaza de uso indebido en perjuicio de la población, tal como se define en la Convención sobre la protección física de los materiales nucleares de 1980; (f) los actos terroristas; (g) el tráfico ilícito o el robo de armas y materiales o dispositivos explosivos; (h) el tráfico ilícito o el robo de vehículos automotores; e (i) la corrupción de funcionarios públicos. (Naciones Unidas, 1998).

Carlos Resa Nastares (s.f.)recoge las definiciones anteriores y, en sus aportes, llega a una definición de crimen organizado que reúne significativas características de las Maras. En los argumentos de Resa Nastares, 
Para que exista un caso de crimen organizado deben aunarse ciertos aspectos tanto del grupo involucrado como de las actividades delictivas a las que se dedican. Entre los primeros destaca el hecho de que se reúna un grupo notable de personas al objeto de cometer de manera constante y permanente actos que son catalogados como delitos en la jurisdicción en la que actúan o allí en donde tengas su base. Galvanizando este conjunto de individuos debe existir una estructura jerárquica, una división de tareas, grados de especialización y ciertas reglas (un sistema de premios y castigos) que rigen el comportamiento de la organización y son impuestas de manera coactiva. Pero si bien una multiplicidad de grupos, como las pandillas juveniles, cumplen estas características en niveles notables, lo que es específico del crimen organizado es su capacidad para protegerse de manera eficaz frente a quienes reten su capacidad de acción, ya sea desde grupos criminales rivales o desde el estado. Esta protección se obtiene, por una parte, a través de la utilización de la violencia o la amenaza creíble de usarla, la intimidación, y, por otra, por la corrupción de funcionarios públicos (Nastares, s.f.).

En otra palabras, el hecho de que las Maras, en particular la Mara Salvatrucha, haya logrado sobrevivir a las Leyes antimaras y las acciones armadas de los ejércitos y policías hondureñas, salvadoreñas y guatemaltecas (incluso mexicanas), hacen que se alejen significativamente del rótulo de simple banda criminal.

Por otro lado, el mismo Resa entra en una contradicción, pues entender las Maras como organizaciones criminales a partir del criterio económico plantea ciertas dificultades. Para Resa (s.f.), "Ios delitos cometidos por la criminalidad común, por diferenciarla del crimen organizado, tienen un carácter predatorio que incorpora una redistribución de unas rentas existentes previamente. En el lado opuesto, el crimen organizado está involucrado en delitos, como la prostitución, el juego o el tráfico de drogas, que abarcan la producción y distribución de nuevos bienes y servicios con la componente de tener un valor añadido". De esta manera se abre la discusión nuevamente sobre el real carácter de las Maras. De hecho, la Agencia de las Naciones Unidas contra la Droga y el Delito ha insistido que tanto la Mara Salvatrucha como la Barrio 18 tienen una participación marginal en el negocio del narcotráfico centroamericano, máxime cuando la mayor cantidad de narcóticos que siguen rumbo a Estados Unidos, lo hacen por vías marítimas que los excluyen de dicha estructura.

Finalmente, Resa Nastares sistematiza la discusión entre delitos simples y crimen organizado, a través de los planteamientos de Naylor, presentados en la tabla 1. Esta sistematización abre nuevamente la discusión de la naturaleza de las Maras, máxime cuando se pueden caracterizar como organizaciones transnacionales, que dirigen sus acciones hacia la sociedad que los ha excluido bien sea por "ser latinos" o por sus características socio económicas, pero sobre todo porque se han desarrollado políticas públicas de seguridad específicamente dirigidas al combate de las Maras y que definen como delito la simple militancia. 
TABLA 1. Diferencias entre el crimen organizado y delitos comunes

\begin{tabular}{|l|l|l|}
\hline & \multicolumn{1}{|c|}{ CRIMEN ORGANIZADO } & OTROS TIPOS DE DELITO \\
\hline Transacción & $\begin{array}{l}\text { Producción y distribución de } \\
\text { nuevos bienes y servicios }\end{array}$ & $\begin{array}{l}\text { Redistribución de la } \\
\text { riqueza existente }\end{array}$ \\
\hline Relaciones & Intercambio multilateral & Transferencia bilateral \\
\hline Intercambio & Consensual & Involuntario \\
\hline Víctimas & iSociedad? & Individuos o empresas \\
\hline Moralidad & Ambigua & No ambigua \\
\hline Política pública & $\begin{array}{l}\text { iCriminalizar la asociación? } \\
\text { ilnterceptar los activos? }\end{array}$ & $\begin{array}{l}\text { Castigar al criminal } \\
\text { Restaurar la propiedad }\end{array}$ \\
\hline
\end{tabular}

Fuente: Naylor, 1997: 4. Citado por Resa Nastares Carlos.

Martínez Ventura (2010: 4), por su parte, ofrece una caracterización interesante sobre crimen organizado. El autor plantea que hay una sinonimia que incluyen los conceptos de criminalidad no convencional, delincuencia especial, criminalidad compleja y macro criminalidad. El autor profundiza en una definición y regresa para esto al sistema de las Naciones Unidas, concretamente la Convención de Naciones Unidas contra el Crimen Organizado Transnacional, conocida como "Convención de Palermo", que dice en su ensayo 2: "Para los fines de la presente Convención: a) Por "grupo delictivo organizado" se entenderá un grupo estructurado de tres o más personas que exista durante cierto tiempo y que actúe concertadamente con el propósito de cometer uno o más delitos graves o delitos tipificados con arreglo a la presente Convención con miras a obtener, directa o indirectamente, un beneficio económico u otro beneficio de orden material" (Martínez, 2010: 4).

Martínez (2010: 4) complementa su discusión sobre crimen organizado, recurriendo al XVI Congreso Internacional de Derecho Penal, de la Asociación Internacional de Derecho Penal, donde se definió al crimen organizado como "un tipo de delincuencia que persigue la obtención de poder y/o lucro a través de una organización fuertemente estructurada." Las características del crimen organizado son: a) la división del trabajo y la disolución de la responsabilidad individual en el seno de la organización; b) la intercambiabilidad de los individuos; c) el secreto; d) la mezcla de actividades legítimas e ilegítimas; e) la capacidad de neutralizar los esfuerzos de aplicación de la ley (por ejemplo por medio de la intimidación, la corrupción); f) la capacidad especial de transferencia de las ganancias."

Estas características son centrales nuevamente para la caracterización de las Maras como organizaciones criminales. Precisamente la división y especialización del trabajo dentro de la Mara es una 
característica central, con mayor visibilidad en la Mara Salvatrucha MS, con mayor estructuración y poder de fuego. El secreto, soportado incluso en sus expresiones sociales y comunicacionales internas como el lenguaje y los tatuajes, y, en particular, la capacidad de neutralizar los esfuerzos de aplicación de la ley permiten pensarlas como organizaciones criminales.

De nuevo, parece ser que el centro de gravedad de la discusión se concentra en la tipificación que se haga de la organización criminal y de las políticas públicas de seguridad específicas que se tomen en contra, en este caso de las Maras. Martínez compara en la Tabla 2 los diferentes requerimientos legales en los casos centroamericanos, permitiendo reforzar la idea que se han construido definiciones de tipo organizacional sobre las Maras.

\section{Tabla 2. Comparación de definiciones jurídicas de crimen organizado}

\begin{tabular}{|c|c|c|c|}
\hline $\begin{array}{l}\text { ONU: Convención } \\
\text { de Palermo (Art. 2) }\end{array}$ & $\begin{array}{l}\text { Guatemala: Ley contra } \\
\text { la delincuencia } \\
\text { organizada (Art. 2) }\end{array}$ & $\begin{array}{l}\text { Costa Rica: Ley } \\
\text { contra la delin- } \\
\text { cuencia organizada } \\
\text { (Art. 1, inc. 19) }\end{array}$ & $\begin{array}{l}\text { El Salvador: Ley contra } \\
\text { el Crimen Organizado } \\
\text { y Delitos de Realización } \\
\text { Compleja (Art. 1, inc. 29) }\end{array}$ \\
\hline $\begin{array}{l}\text { "Para los fines de la } \\
\text { presente Conven- } \\
\text { ción: a) Por "grupo } \\
\text { delictivo organiza- } \\
\text { do" se entenderá } \\
\text { un grupo estructu- } \\
\text { rado de tres o más } \\
\text { personas que exis- } \\
\text { ta durante cierto } \\
\text { tiempo y que ac- } \\
\text { túe concertada- } \\
\text { mente con el pro- } \\
\text { pósito de cometer } \\
\text { uno o más delitos } \\
\text { graves o delitos } \\
\text { tipificados con } \\
\text { arreglo a la presen- } \\
\text { te Convención con } \\
\text { miras a obtener, di- } \\
\text { recta o indirecta- } \\
\text { mente, un bene- } \\
\text { ficio económico u } \\
\text { otro beneficio de } \\
\text { orden material; } \\
(. . .) \text { " }\end{array}$ & $\begin{array}{l}\text { "Para efectos de la presente Ley } \\
\text { se considera grupo delictivo } \\
\text { organizado u organización cri- } \\
\text { minal, a cualquier grupo estruc- } \\
\text { turado de tres o más personas, } \\
\text { que exista durante cierto tiem- } \\
\text { po y que actúe concerta- } \\
\text { damente, con el propósito de } \\
\text { cometer uno o más de los deli- } \\
\text { tos siguientes: (...) } \\
\text { Lo anterior, con la finalidad de } \\
\text { obtener, directa o indirecta- } \\
\text { mente un beneficio económi- } \\
\text { co o de cualquier índole para } \\
\text { sí o para tercero. } \\
\text { Por grupo estructurado se en- } \\
\text { tenderá un grupo no formado } \\
\text { fortuitamente para la comisión } \\
\text { inmediata de un delito y en el } \\
\text { que no necesariamente se } \\
\text { haya asignado a sus miembros } \\
\text { funciones formalmente defini- } \\
\text { das ni haya continuidad en la } \\
\text { condición de miembro o exis- } \\
\text { ta una estructura desarrollada." }\end{array}$ & $\begin{array}{l}\text { "Entiéndese por } \\
\text { delincuencia orga- } \\
\text { nizada, un grupo } \\
\text { estructurado de } \\
\text { dos o más perso- } \\
\text { nas que exista du- } \\
\text { rante cierto tiempo } \\
\text { y que actúe con- } \\
\text { certadamente con } \\
\text { el propósito de co- } \\
\text { meter uno o más } \\
\text { delitos graves." }\end{array}$ & $\begin{array}{l}\text { "Se considera crimen orga- } \\
\text { nizado aquella forma de de- } \\
\text { lincuencia que se caracteriza } \\
\text { por provenir de un grupo es- } \\
\text { tructurado de dos o más per- } \\
\text { sonas, que exista durante } \\
\text { cierto tiempo y que actúe } \\
\text { concertadamente con el } \\
\text { propósito de cometer uno o } \\
\text { más delitos. } \\
\text { Para los efectos de la presen- } \\
\text { te Ley, constituyen delitos de } \\
\text { realización compleja los } \\
\text { enumerados a continuación, } \\
\text { cuando se cumpla alguna de } \\
\text { las circunstancias siguientes: } \\
\text { Que haya sido realizado por } \\
\text { dos o más personas, que la } \\
\text { acción recaiga sobre dos o } \\
\text { más víctimas, o que su per- } \\
\text { petración provoque alarma } \\
\text { o conmoción social. Dichos } \\
\text { delitos son: a) Homicidio } \\
\text { simple o agravado; b) Se- } \\
\text { cuestro; y, c) Extorsión." }\end{array}$ \\
\hline
\end{tabular}

Fuente: Martínez (2010: 5). 
Martínez, sin embargo, es enfático a la hora de alejar, al menos parcialmente, a las Maras del concepto de crimen organizado. Para el autor,

Las maras actualmente configuran una mezcla de fenómeno social con derivaciones delictivas. Por un lado, siguen siendo ante todo una problemática social en la medida en que la mayoría de sus integrantes, especialmente los más jóvenes, continúan dentro de estas estructuras porque las maras son un espacio de identidad, protección y pertenencia que no encuentran en la familia, la escuela o la comunidad. Igualmente, los motivos por los que los jóvenes, adolescentes y niños de edades cada vez menores, deciden ingresar o son "reclutados" siguen siendo los múltiples factores sociales, económicos, políticos, culturales y circunstanciales antes mencionados, que lejos de mejorar han empeorado en los últimos veinte años. Pero al mismo tiempo, las maras son fuente de actividades criminales cada vez más extendidas, puesto que dentro de ellas existen estructuras o individuos que cometen todo tipo de crímenes, entre los cuales las extorsiones se han convertido en la base de lo que puede denominarse la economía criminal de las pandiIlas, que no es más que una de las múltiples variedades de los llamados mercados ilegales. Esto no convierte a las maras en grandes agrupaciones mafiosas, capaces de hegemonizar los mercados delictivos. Es insostenible decir que las maras dirigen o controlan el narcotráfico, el tráfico de armas, la trata de personas, el lavado de dinero y otras expresiones de la criminalidad no convencional; para dominar esos grandes rubros del mercado criminal se debe contar con un nivel educativo, posición social, poder político y capacidad económica que no poseen estos individuos. (Martínez, 2010).

Este análisis sin embargo no distingue entre la Mara Salvatrucha y la Mara Barrio 18. Precisamente en Bonilla (2008) se establecen diferencias sustanciales entre ellas, concluyendo que es más cercano definir a la Mara Salvatrucha MS como organización criminal, a diferencia de la Barrio 18.

\section{Cuadro 1. CARACTERÍSTICAS ESPECÍFICAS}

\begin{tabular}{|l|l|}
\hline \multicolumn{1}{|c|}{ MARA SALVATRUCHA } & \multicolumn{1}{c|}{ MARA BARRIO 18 } \\
\hline $\begin{array}{l}\text { Alta capacidad y creatividad organizativa, ex- } \\
\text { pansión internacional, alta movilidad, víncu- } \\
\text { los con tráfico de drogas, armas y personas }\end{array}$ & $\begin{array}{l}\text { Disciplina interna rigurosa, rol especial de las mujeres, } \\
\text { vínculos con tráfico de armas y drogas, colaboración } \\
\text { con organizaciones de secuestro y robo de bancos }\end{array}$ \\
\hline Redes de inteligencia e infiltración & Vínculos con organizaciones mexicanas \\
\hline Objetivos a corto y mediano plazo & \\
\hline $\begin{array}{l}\text { Capacidad para adaptarse al endurecimien- } \\
\text { to policial }\end{array}$ & Mayor capacidad de encubrimiento y disimulo \\
\hline
\end{tabular}

Fuente: Bonilla (2008). 
Por otro lado, una organización de crimen organizado, para Abadinsky, puede definirse como "una empresa no ideológica que envuelve un grupo de personas en una muy cerrada interacción social, organizada sobre una base jerárquica de al menos tres niveles o rangos, con el propósito de ofrecer seguridad e incrementar el poder a través de actividades legales o ilegales." (Howard, 1997: 6).

Específicamente, Abadinsky propone 8 características centrales para delimitar la acción de las Organizaciones Criminales. En primer lugar, su carácter meramente empresarial y no ideológico; en segundo lugar, su carácter específicamente jerárquico; en tercer lugar, la organización debe tener un sistema de membrecía, ingreso o pertenencia limitado; en cuarto lugar, la organización busca perpetuarse en su actividad criminal; en quinto lugar, la organización es extremadamente violenta y se interesa por hacer demostraciones de violencia para amedrentar a la sociedad, a los clientes y a la competencia; en sexto lugar, la organización debe contar con una demostrada especialización o división del trabajo; en séptimo lugar el ejercicio y la existencia de la organización de crimen organizado se proyecta monopolísticamente; y finalmente tiene un código o reglas que permiten caracterizar y formalizar requisitos de ingreso, permanencia, tramitar órdenes y facilitar la operatividad (1997: 4).

En este orden de ideas, las Maras representan una organización extremadamente violenta, que ofrece protección a sus miembros, al punto de construir relaciones de lealtad más estrechas que en una familia. Sobre esta relación, Santamaría afirma que "Tradicionalmente, las pandillas suelen agrupar a jóvenes que se reúnen para defender el barrio contra la pandilla contraria, participar en actividades delictivas que reditúan en ganancias para la pandilla (generalmente usadas para el consumo de drogas o para entretenimiento) o simplemente para "pasarla bien" y ser parte de un colectivo que, para muchos de ellos, representa su verdadera familia." (Santamaria, 2010). Este sentido de pertenencia se afianza desde sus orígenes cuando las pandillas en Estados Unidos agruparon principalmente jóvenes de origen latino, provenientes de diferentes oleadas migratorias que iniciaron en los 70 y que encontraron en la Organización una forma de protegerse frente a exclusiones xenofóbicas o amenazas de otras bandas. La Mara 18, originada en Los Ángeles, se convirtió especialmente, junto con la Mara Salvatrucha, en las principales confederaciones que agruparon y protegieron a estos jóvenes inmigrantes. Un segundo factor para que se identifique la lealtad hacia las Maras es que las oleadas de inmigración de los años 80 presionaron a la desintegración de muchas familias centroamericanas, de manera que se constituían familias con lazos débiles, donde la cabeza era normalmente el abuelo, en ausencia de los padres que habían migrado a Estados Unidos, y unos jóvenes sin expectativas ni control (Santamaria, 2010). Esta situación es desarrollada por Abadisnky (1997: 296,304) al plantear su explicación de Crimen Organizado, en nuestro caso, sobre las Maras, como productos de subculturas, desorganización social y anomias, con un efecto ampliado para las Maras de origen estadounidense de los 70 soportado en motivaciones étnicas. 
En cuanto a la segunda característica, el control jerárquico de la Mara es una de las características más fuertes. Siguiendo a Abadinsky, las Maras, tanto la 18 como la Salvatrucha o MS, representan un modelo burocrático/corporativo en toda su extensión. Esto se evidencia en el hecho de que existe una completa división y especialización del trabajo que facilita el control jerárquico. Cada Mara, la 18 y la MS, tiene un "palabrero" o "primera palabra", que constituye el líder máximo, que desde Los Ángeles controla las "Clikas" o células de la pandilla en El Salvador, Honduras y Guatemala, principalmente. Al interior de cada ciudad, existe un líder menor que se encarga de organizar los diferentes minigrupos barriales. Al interior de cada barrio, existe un líder operativo, que se encarga de la aplicación inmediata de la violencia, de controlar ingresos, asignar tareas a los mareros y ejecutar las órdenes que han sido transmitidas por el líder de la ciudad o incluso por el "palabrero" (Falkenburger: s.f.: 52). Existe, por otro lado, una discusión académica muy amplia a este respecto, donde se ven argumentos que incluso ponen en duda la existencia de estructuras de comando y control de las Maras y los plantean más bien como franquicias (Manrique, 2006). Sin embargo, es muy difícil concluir que se trata de actividades armadas desagregadas.

Por lo tanto, la jerarquía implica obediencia y ésta, dentro de la Mara se constituye en el principal factor de cohesión. Así si se analiza el tercero de los factores propuestos por Abadinsky: la admisión y permanencia están completamente reguladas. El líder puede determinar que al ingreso a la Mara, el candidato opte por una demostración de violencia que incluya un asesinato, o si se trata de una aspirante, puede incluir también el ejercicio de la violencia, si tiene un compañero al interior de la Mara, o si es soltera, actividades sexuales con el líder del barrio o con la persona o personas que este determine. El retiro de la Mara es mucho más difícil, pues el vínculo es permanente. Solamente las mujeres mareras que se encuentren en embarazo pueden optar por retirarse parcial o totalmente si su situación así lo requiere. Santamaría (2010) explica que las reglas de ingreso y salida de la Mara, así como las normas de comportamiento al interior de la misma, [son] más estrictas para garantizar la protección y la lealtad entre los miembros activos. La mara se constituye así en el ethos grupal, y los diferencia así de otras organizaciones. (Martínez R., s.f.).

Es importante indicar que a pesar de que la violencia desarrollada por las Maras y su dedicación a actividades criminales implican el control de pequeñas actividades de extorsión y producción ilegal de recursos, no hay pruebas contundentes de su participación en actividades mayores como el narcotráfico. Según la Oficina de las Naciones Unidas contra la Droga y el Delito, no existe una correlación funcional entre los canales de tráfico de narcóticos hacia Estados Unidos y las Maras en Centroamérica. La principal razón para construir esta duda, es que la mayor parte de las rutas de tráfico de narcóticos son aéreas o marítimas, y si incluyen un componente terrestre, este se da en México (UNODOC, 2007). 
La participación, por lo tanto, en actividades de crimen organizado de las Maras se concentran más en el control de actividades delincuenciales ordinarias, el microtráfico de narcóticos, el sicariato y en mucha menor medida la extorsión. Así, se requiere una estructura burocrática compleja pero no se sumerge en el espectro de la privatización y oferta de los servicios de la protección, que es una característica fundamental de las mafias.

Un segundo elemento para definir a las Maras como una estructura de crimen organizado radica en el hecho de su deslocalización. Una simple pandilla tiene un referente barrial inmediato y sus actividades se limitan a ejercer un control territorial definido y a impedir el ingreso de otras pandillas. El caso de las Maras sin embargo es diferente. En primer lugar, el hecho de que sea un grupo originado en Estados Unidos a través de diferentes procesos migratorios ${ }^{1}$ hizo que

1. Santamaría enumera estos procesos migratorios, afirmando que "El primer momento se desarrolla durante la segunda mitad del siglo xx en dos escenarios geográficos distintos. Por un lado, en Los Ángeles surgen y se expanden las pandillas de origen latino conformadas en su mayoría por comunidades migrantes de mexicanos de primera o segunda generación. La Mafia mexicana y la misma pandilla del Barrio 18, por ejemplo, surgen como pandillas con un fuerte componente de reivindicación étnica que cobra sentido en un escenario de fuerte racismo, hostilidad y exclusión, que enfrentan las comunidades de migrantes latinos en las grandes ciudades estadunidenses. De ahí que, en un primer momento, uno de los símbolos más recurrentes de la pandilla del Barrio 18 sea precisamente la imagen de la Virgen de Guadalupe (tan presente en el imaginario de "lo mexicano") o el uso de los tres colores de la bandera nacional de México. El otro escenario tiene lugar en los países del norte de Centroamérica y está caracterizado por un proceso acelerado de urbanización que genera, entre otras cosas, el surgimiento de pandillas locales que operan de manera atomizada y que tienen un margen de operación circunscrita al barrio o a la colonia.

El segundo momento se da durante la década de los años ochenta. Este periodo, que inaugura el primer capítulo de la historia transnacional de las Maras, se caracteriza por la llegada masiva de niños y jóvenes centroamericanos a Estados Unidos a causa de los cruentos enfrentamientos armados (en el caso de Guatemala y El Salvador) o de la fuerte violencia social que se vivía en sus países de origen (como fue el caso de Honduras). Ante la exclusión social y la discriminación que enfrentaban varios de estos niños y jóvenes en algunas ciudades de Estados Unidos, las pandillas latinas representaban un espacio atractivo para ganar respeto y también para protegerse de otros grupos delictivos que existían en los barrios marginales. Fue así que estos jóvenes centroamericanos ingresaron a las pandillas ya existentes, como la pandilla del Barrio 18, conformada inicialmente sólo por migrantes de origen salvadoreño, y la otra gran confederación de las maras: la Mara Salvatrucha. La tercera "oleada migratoria" se da en los años noventa, después de los procesos de paz en Centroamérica. La oficina del entonces Ilamado Servicio de Inmigración y Naturalización de los Estados Unidos deportó a miles de migrantes de origen centroamericano, aludiendo razones de seguridad. El proceso fue desordenado y abrupto, y no estableció mecanismos de coordinación que permitieran a los países receptores identificar de manera efectiva a los deportados que tuvieran antecedentes penales. El cuarto y último momento se da a fines de la década de los años noventa y se extiende hasta la actualidad. Tanto la crisis económica como los efectos devastadores del huracán Mitch de 1998 generan otro éxodo importante de centroamericanos que, en su ruta hacia Estados Unidos, prolongan su periodo de paso por México. 19 La tendencia se reafirma a partir de 2003 con la implementación de las políticas de mano dura o cero tolerancia. Bajo distintos nombres (Plan Mano Dura y Súper Mano Dura en El Salvador; Plan Escoba, en Guatemala, o Plan Libertad Azul en Honduras), estos programas tienen como denominador común privilegiar la represión y el combate directo de las pandillas como método para disminuir la violencia juvenil. (Gema, 2010, págs. 9, 11).

Luis Alexander Montero Moncada - Liana Abril Pérez - Ángela Herrera 
existiera un origen común, relacionado a lo étnico, que impulsaba a reivindicar una identidad latina en lugar de una mera identidad local. Es llamativo el hecho de que las primeras Maras, especialmente la 18, utilizaran en su parte estética la imagen de la virgen de Guadalupe, y no incluyeran un referente más especifico de Honduras, el Salvador o Nicaragua.

En segundo lugar, la transnacionalización de las Maras a casi toda Centroamérica y el sur de México, hacen que la lealtad no sea con una organización que tiene una única visibilidad local, sino que existe transversalmente en varios países con sociedades similares. Así un marero será marero tanto en Honduras como en Guatemala o en Chiapas. En un momento inicial, esta deslocalización se soportó sobre la imagen de latinidad y en una estética muy recursiva que marcaba los cuerpos de los mareros y los hacía visibles en sus ritos, obligaciones e incluso en sus manifestaciones de violencia. De hecho, al inicio, los integrantes de la Mara 18 debían añadir un tatuaje en forma de lágrima por cada muerte que hubieran producido. Luego de la construcción de las leyes antimaras en Centroamérica, los tatuajes se han hecho menos viables, pues la sola evidencia de alguno de estos grupos se constituye en elemento probatorio para conllevar a una detención. Luego de estas implementaciones legales, la deslocalización se realiza a través de redes complejas que se soportan en el secreto, la tecnología y en una adecuada especialización de funciones y jurisdicciones de las instancias de la Mara, características propias de Organizaciones del Crimen (Ministerio de Seguridad Pública y Justicia. República de El Salvador, 2001).

Como conclusión preliminar, es posible indicar que las Maras se acercan bastante a la definición sobre Crimen Organizado del FBI recogida por Abadinsky. Dicha definición plantea que "cualquier grupo que haya formalizado una estructura y cuyo objetivo primario sea obtener dinero a través de actividades ilegales, se constituye como una estructura de crimen organizado. Dichos grupos mantienen su posición a través del uso de la violencia o la amenaza de su uso, corrupción pública y tiene un gran impacto sobre la población en sus sitios de dominio." (1997: 3). Nótese sin embargo que esta definición no enmarca el uso de la violencia dentro de la oferta de la violencia como un servicio privado. Toda estructura criminal es violenta, pero no toda vende servicios de violencia.

\section{MAFIOSOS Y DELINCUENTES. LA DIFERENCIA ENTRE EL PRESTIGIO Y EL TERROR}

Bajo los planteamientos de Dickie y Gambeta, uno de los elementos característicos de las mafias, en principio las italianas (o si se quiere explícitamente la mafia siciliana) y posteriormente las ítalo-americanas, es el hecho de constituir un universo de sentido basado en tradiciones, costumbres o incluso valores sociales que van a ser reproducidos en el comportamiento criminal de 
la mafia. Así se llega, por ejemplo, al concepto de Omertá o al prestigio social del mafioso siciliano original de fines del siglo XIX, quien incluso complementaba o a veces reemplazaba al Estado en la solución de problemas comunes.

Este prestigio, en otras organizaciones criminales o mafias que constituyen este objeto de estudio, se da por otras vías. En al caso de los Zetas, la generación de sentido se ha acompañado por una construcción propia de códigos, desde un escudo hasta distinciones y medallas.

Por otro lado, el uso eficiente de la violencia (extrema de ser necesario) acompañada de una visibilidad comunicacional de sus acciones han trascendido no solo entre su competencia sino al interior de sus posibles clientes. Acciones como el asesinato de la cúpula de Los Texas o el intento de rescate de Osias Cárdenas Guillén, donde se incluyeron un par de helicópteros y armamento especializado, hicieron que las demostraciones armadas de los Zetas tuvieran un particular eco. Adicionalmente, a nivel organizacional, los Zetas manejan un sistema simplificado de división y especialización de funciones, asignando indicativos a sus integrantes en función de su importancia dentro de la estructura, que va desde Z1 al comandante, Z2 al subcomandante hasta Z5 al mando operativo.

Las Maras, por otra parte, no expresan ni se interesan por lograrlo un prestigio más allá del concebido para sus propios integrantes al interior de la organización. Su imagen exterior se reduce a la criminalidad funcional, de manera que sus rituales o valores pasan desapercibidos en la mayoría de los casos y, de conocerse, remiten al miedo.

En segundo lugar, la actividad económica de las Maras no tiene paralelo legal, ya que sus actividades de extorsión, microtráfico y sicariato las encierran en la economía ilegal. Por su parte, los Zetas se dedican no solo a la venta privada del servicio de la violencia, sino que controlan otras actividades ilegales, legales y cuestionables, como se mencionó al inicio del ensayo. De esta manera, la estructuración y orientación económica de los Zetas los ubica en un nivel más adelantado en la categorización mafiosa que las Maras.

En términos concretos, Reuter plantea que a través de la "publicidad" o, en otras palabras, por medio de la visibilidad, incrementa su margen de acción para monopolizar la violencia y el acceso a mercados y recursos económicos, y, a la vez, obligar al Estado a gastar un dinero desproporcionadamente mayor en su combate. Para Reuter, la monopolización de la actividad criminal, soportada en la visibilidad, prestigio y violencia aseguran el acceso y control de recursos económicos, características demostradas por Los Zetas. (1984: 135,139). 


\section{RETOS ASIMÉTRICOS PROPUESTOS POR LA CRIMINALIDAD Y LA MAFIA}

La definición de amenaza asimétrica, por no decir guerra asimétrica, es relativamente nueva. Las primeras menciones teóricas que apuntaban a definir este espacio aparecieron a finales de los 80, cuando se publicó un ensayo en la Marine Corps Gazette, escrito por el CO. Nigthtendale, CO Sutton, TC Wilson y el CT Schmitt, donde se hacía referencia a los "riesgos de cuarta generación", o en otras palabras, nuevos retos militares diferentes a los existentes durante la guerra fría. Posteriormente es posible encontrar una definición construida en la OTAN(Marquina, 2004), donde se caracteriza el empleo de la fuerza en el campo operacional, basados en la movilidad, capacidad de proyección, sostenibilidad, disponibilidad, superioridad en el enfrentamiento, énfasis en inteligencia, modularidad, flexibilidad y la posibilidad de operar en red.

Dentro de esta conceptualización, agrupaciones como las Maras y fundamentalmente los Zetas, se convierten en sujetos de la asimetría, fundamentalmente por la concepción armada que han construido y por la ampliación de los alcances organizacionales de cada una de estas estructuras.

Partiendo del hecho que la guerra asimétrica involucra múltiples esferas de acción, que van desde las políticas, jurídicas, sociales, culturales, diplomáticas, económicas y hasta religiosas, hasta llegar a la acción militar propiamente dicha, se puede concluir que ambas estructuras han comprendido dicha multiplicidad y direccionan sus esfuerzos a tal fin. La orientación barrial de las Maras, donde se hace un reemplazo de la familia y se reconfiguran los valores de sus integrantes, reflejan precisamente el impacto social y cultural de la organización, llegando al punto de proponer una forma de vida para sus integrantes, que no termina sino hasta la muerte. Las Maras ofrecen no solo formas de reemplazar relaciones familiares, sino que también comprometen a sus miembros ofreciéndoles aparentes beneficios como educación y absorción laboral. Obviamente, el resultado de la acción social, económica o sicológica de las Maras, se va a ver traducida en una lealtad consolidada de sus miembros, que se lleva al campo criminal y de la violencia.

Por el lado de los Zetas, su delimitación como amenaza asimétrica es mucho más clara. Su origen en las fuerzas de seguridad mexicanas como grupo especial, la especialización de sus acciones militares y una concepción organizacional propia de las agrupaciones de fuerzas especiales, hacen que los Zetas absorban con mayor profundidad la concepción asimétrica. Se han configurado como un grupo de fuerzas especiales al servicio de la criminalidad, logrando adaptarse al ambiente clandestino y encontrando reemplazos en ese mundo a los apoyos que una unidad de fuerzas especiales tiene desde la legalidad. Así pues, los Zetas han construido estructuras de apoyo en inteligencia, al acceder a medios de comunicación y políticos, y de apoyo 
logístico y de abastecimientos al enlazarse con redes de tráfico de armas y municiones, generalmente, desde Estados Unidos. Adicionalmente se logra un apoyo legal a la hora de permear sectores políticos.

La acción de los Zetas como unidad especial, trasciende lo militar y se ve reforzada por "campañas" mediáticas que buscan incidir en esferas sociales y culturales de la sociedad mexicana. En ese sentido se pueden observar esfuerzos por transbordar ideológicamente a otros miembros activos de las fuerzas de seguridad mexicanas para que engrosen las filas de la organización mafiosa. Los Zetas venden no solo una imagen de generadores de violencia y protección, sino también de eficiencia y efectividad en su acción militar, su poder de fuego y su influencia en sectores sociales y políticos de México. Venden también una imagen de reivindicación económica para los soldados mexicanos, que desde la ilegalidad obtendrían más recursos que desde la institucionalidad legal (Gráfico 2). Lo peligroso de todo esto, es que este perverso mensaje cala con alguna facilidad, llevando al incremento en el tamaño de ésta organización y a la complejidad para su enfrentamiento. Incluso, es posible observar incursiones de Los Zetas a nivel continental, por ejemplo en sus lazos con las FARC, consolidando así su característica de operar en red e incidir en la estabilidad regional en materia de seguridad, pasando de ser una amenaza asimétrica exclusiva para el Estado Mexicano a ser un interrogante hemisférico.

\section{CONCLUSIONES}

Para finalizar, es posible afirmar que las dos estructuras objeto de estudio ofrecen un panorama interesante para hacer un ejercicio comparado entre la definición tradicional de mafia y la de crimen organizado, permitiendo ubicar a los Zetas como estructura mafiosa y a las Maras como estructuras de crimen organizado. No obstante, la falta de consenso amplio sobre la definición, particularmente de crimen organizado y la frontera cada vez más etérea entre la privatización del ejercicio de la violencia y el delito no ideológico, dificultan una clasificación categórica de estos dos grupos.

En cuanto a la valoración que se puede hacer de estas estructuras dentro de un marco asimétrico, se puede concluir que las dos se fundamentan en una lógica de conflicto nuevo, donde se privilegia ya no el poder militar equivalente al del Estado o al adversario para plantear una confrontación directa, sino que se desagregan los factores de poder en económicos, sociales, culturales, políticos y judiciales y se privilegia una acción militar especializada. Así, tanto los Maras como los Zetas son amenazas asimétricas y pueden, debido a su orientación urbana, rasgos de oferta cultural y movilización social y definitivamente, por su capacidad de conformar redes, aún por fuera de su territorio, llegar a ser tenidas en cuenta como amenazas regionales o incluso transnacionales. 


\section{REFERENCIAS}

- Bonilla, O. (2008). Pandillas Amenaza Transnacional. Consejo Nacional de Seguridad Pública - República de El Salvador. Washington: Misión Permanente de El Salvador ante la OEA.

- $\quad$ Dickie, J. (2007). Historia de la Mafia Siciliana. La Cosa Nostr. Madrid: Editorial de Bolsillo.

- $\quad$ Falkenburger, E. $(\mathrm{s}, \mathrm{f})$. Thale Geoff. Maras y Pandillas Juveniles: dos mundos diferentes. Revista Cidob d'Afers Internacionals, 81, 52.

- Gambeta, D. (2010). La Mafia Siciliana. El negocio de la protección privada. México: Fondo de Cultura Económica.

- Gema, S. (2010). Maras y Pandillas: límites de su transnacionalidad. Revista Mexicana de Política Exterior, 101,123.

- Howard, A. (1997). Organized Crime. Nelson . Chicago: Hall Publishers.

- Manrique, L. E. (25 de Julio de 2006). Un poder paralelo: el crimen organizado en América Latina. Real Instituto Elcano. Recuperado el 7 de julio de 2012 de http:// www.realinstitutoelcano.org/wps/portal/rielcano/contenido?WCM_GLOBAL_CONTEXT=/ elcano/elcano_es/zonas_es/ari+84-2006

- Marquina, A. (2004). La revisión estratégica de la defensa: las misiones de las Fuerzas Armadas, Las fuerzas Armadas del siglo XXI. Estados Unidos: UNISCI Discussion Papers.

- Martínez, J. (2010). Maras en El Salvador y su relación con el crimen organizado transnacional. Programa de Cooperación en Seguridad Regional. Fundación Friedrich Ebert Stiftung .

- $\quad$ Martínez, R. (s.f.). Introducción. Revista Cidob d’Afers Internacionals, 81, 13.

- Ministerio de Seguridad Pública y Justicia. República de El Salvador. (2001). Reporte de las Pandillas en El Salvador. República de El Salvador: Ministerio de Seguridad Pública y Justicia. República de El Salvador.

- $\quad$ Naciones Unidas. (1998). Convención de las Naciones Unidas contra el tráfico ilícito de estupefacientes y sustancias psicotrópicas de 1998. Recuperado el 6 de Noviembre de 2010, de http://www.unodc.org/pdf/convention_1988_es.pdf. 
- Nastares, C. R. (s.f.). El comercio de las drogas ilegales en México Los Zetas, de narcos a mafiosos. Recuperado el 30 de Septiembre de 2010 de: http://www.uam.es/personal_pdi/ economicas/cresa//nota0403.pdf

- Resa, C. (s.f.). Crimen Organizado Transnacional: Definición, causas y consecuencias. Recuperado el 17 de Noviembre de 2010 de http://www.securitytransformation.org/ images/documentos/345_crimen-org_oricausconsec.pdf

- $\quad$ Reuter, P. (1984). Disorganized Crime. The Economics of the Visible Hand.Estados Unidos: MIT Press.

- UNODOC. (2007). Crimen y Desarrollo en Centroamérica. Atrapados en la encrucijada. Esatados Unidos: Naciones Unidas. 